\title{
Upstream to downstream: a multiple-assessment-point approach for targeting non-point-source priority management areas at large watershed scale
}

\author{
L. Chen, Y. Zhong, G. Wei, and Z. Shen \\ State Key Laboratory of Water Environment Simulation, School of Environment, Beijing Normal University, \\ Beijing 100875, People's Republic of China \\ Correspondence to: Z. Shen (zyshen@ bnu.edu.cn), L. Chen (chenlei1982bnu@ bnu.edu.cn)
}

Received: 20 November 2013 - Published in Hydrol. Earth Syst. Sci. Discuss.: 29 November 2013

Revised: - Accepted: 16 February 2014 - Published: 1 April 2014

\begin{abstract}
The identification of priority management areas (PMAs) is essential for the control of non-point-source (NPS) pollution, especially for a large-scale watershed. However, previous studies have typically focused on small-scale catchments adjacent to specific assessment points; thus, the interactions between multiple river points remain poorly understood. In this study, a multiple-assessment-point PMA (MAP-PMA) framework was proposed by integrating the upstream sources and the downstream transport aspects of NPS pollution. Daning River watershed was taken as a case study in this paper, which has demonstrated that the integration of the upstream input changes was vital for the final PMAs map, especially for downstream areas. Contrary to conventional wisdom, this research recommended that the NPS pollutants could be best controlled among the upstream highlevel PMAs when protecting the water quality of the entire watershed. The MAP-PMA framework provided a more costeffective tool for the establishment of conservation practices, especially for a large-scale watershed.
\end{abstract}

\section{Introduction}

Unlike point-source pollution, non-point-source (NPS) pollution varies greatly at multiple spatial and temporal scales, making it difficult and costly to identify and alleviate (Kovacs et al., 2012; Squillace and Thurman, 1992). As widely accepted concepts, priority management areas (PMAs) are defined as those areas where the risk potential of certain pollutants exceeds local loss tolerance or con- tributes more pollutant to the nearby water body (Carpenter et al., 1998; Ghebremichael et al., 2013). Many successes of the NPS control efforts have been reported based on PMAs (Ghebremichael et al., 2010; Kovacs et al., 2012; Setegn et al., 2006; Strauss et al., 2007; Tripathi et al., 2003; White et al., 2009; Whitehead et al., 2007; Yeghiazarian et al., 2006; Zhou and Gao, 2011). Today, the targeting of watershed PMAs has been integrated as an inherent part of largescale watershed management programs, such as the Total Maximum Daily Load (TMDL) (Savage and Ribaudo, 2013; Sahoo et al., 2013; White et al., 2009).

As a geographically connected unit, a watershed can be broken into a distinct stream network and corresponding subwatersheds (Gérard-Marchanti et al., 2006; Liu and Weller, 2008; Miller et al., 2013). A river assessment point, where water quality is sampled and evaluated, is usually designed as the key variable in assessing and protecting water quality within a river network (Lee et al., 2012). A typical assessment point is placed at the outlet of a key sub-watershed or tributary, a specific location of interest, or other key physical boundary, such as the downstream node of a stream segment (Brown and Barnwell, 1987; Lee et al., 2012). Despite the potential advantages of watershed-scale PMAs, watershed management programs and related funds currently focus on high-pollutant-loss areas that are of small scale or within a specific district. This idea is derived from the land resource perspective, which brings local collaborators into the cost share programs. However, from a water quality perspective, the scientific basis of these watershed management programs has long been questioned because these 
approaches cannot address the water quality at multiple assessment points, especially for large-scale watersheds.

Previous studies have demonstrated the impact of those sensitive areas on the water quality at certain assessment points. For example, Meybeck (1998) reported that most PMAs of nitrogen $(\mathrm{N})$ were located along small agricultural streams, while the loss potential of phosphorus $(\mathrm{P})$ was higher when adjacent to the watershed outlet. However, the impacts of these spatial units on the water quality vary greatly among multiple assessment points. Böhlke and Denver (1995) found that there was a decreasing impact of the drainage areas from upstream to downstream in the Atlantic Coastal Plain, USA. Alexander et al. (2000) analyzed the monitoring data collected from 374 river assessment points in the USA, and their results showed the P loss declined from the main channel to the tributary. Prasad et al. (2005) further demonstrated that multiple river assessment points integrated the source and transport aspects of NPS pollution at the watershed scale. These studies have improved our understanding of the spatial variability of PMAs at the catchment scale (Hefting et al., 2006). However, the nature of the interactions among those multiple river points still remains poorly understood. The relationship between the upstream and downstream assessment points has yet to be developed for those large-scale watersheds (Horton, 1945; Kang et al., 2008; Meynendonckx et al., 2006; Rodriguez-Iturbe and Rinaldo, 1997).

One solution is to identify those sensitive areas responsible for disproportionate load contributions to the pollutant fluxes at multiple river assessment points (Behera and Panda, 2006). The aim of this paper is to establish a multipleassessment-point PMA (MAP-PMA) framework for a more cost-effective allocation of PMAs. In this new framework, the respective impacts of each spatial unit on multiple assessment points were considered instead of those deterministic areas adjacent to a specific river point. An innovative approach is presented here, which integrates the response of downstream water quality to the corresponding variation of upstream inputs.

\section{Materials and methods}

\subsection{Study watershed description}

The Daning River watershed $\left(108^{\circ} 44^{\prime}-110^{\circ} 11^{\prime} \mathrm{E}, 31^{\circ} 04^{\prime}-\right.$ $31^{\circ} 44^{\prime} \mathrm{N}$ ), which is located in the northeast part of the Three Gorges Reservoir Area (TGRA), China, was selected as the study area. The drainage area of this watershed is $2422 \mathrm{~km}^{2}$, and the geological formation is dominated by mountains $(95 \%)$ and low hills (5\%), with elevations ranging from $2588 \mathrm{~m}$ in the north to $200 \mathrm{~m}$ in the south. In this watershed, the headwater areas are characterized by high relief and valley gradients, which are conducive to the transport of NPS pollutants. The middle and low catchments exhibit

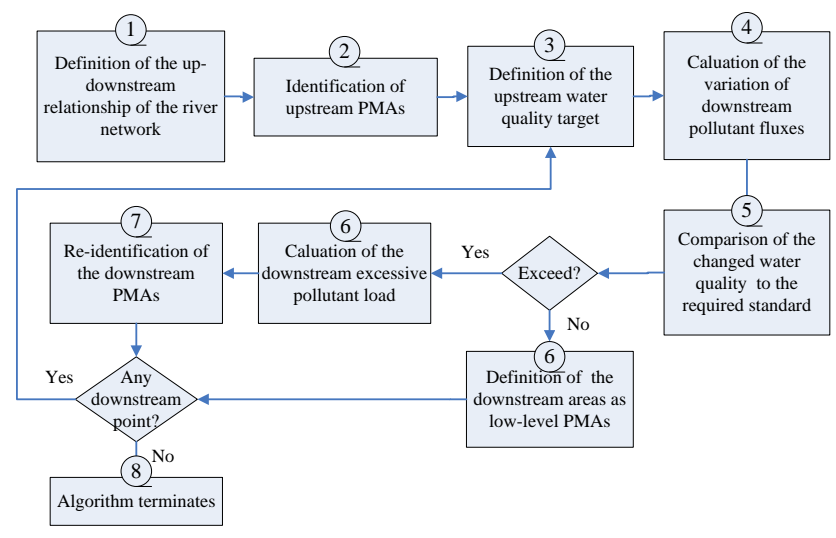

Fig. 1. The framework of the MAP-PMA.

low-gradient alluvial channels bounded by agricultural areas. The local climate is temperate and humid, with an average annual precipitation of $1124 \mathrm{~mm}$. The land cover types that dominate the watershed are forest $(65.8 \%)$, agricultural area $(22.2 \%)$, and grassland $(11.4 \%)$.

In the TGRA, point-source pollution is insignificant owing to the absence of large sewage systems and strict regulations. However, NPS pollution remains largely unregulated and accounts for a large share of the pollutant release into eutrophic water bodies (Wu and Zheng, 2013). Eutrophication, in terms of algae blooms, has increased eightfold in the TGRA since 1990, and a particular emphasis has been placed on NPS-P. In our previous studies (Gong et al., 2011; Shen et al., 2012, 2013), the upstream areas of the Wuxi station (labeled as AP1 in this research) have served as a study area. For the purpose of comparison, both of the upstream areas of AP-1 and the watershed outlet (labeled as AP-2) were selected as the study area (Fig. 2a), and the targeting results were based on the load contributions of each sub-watershed to the $\mathrm{P}$ fluxes at AP-1 and AP-2.

\subsection{The MAP-PMA framework}

The MAP-PMA framework, which integrates the interactions between multiple river points from upstream to downstream, is shown in Fig. 1. The upstream PMAs are first identified based on the required load reduction at the upstream assessment point. Then, the downstream PMAs are identified by the variations of pollutant fluxes at the downstream river point. In the end, each required load reduction is separated into its origin sources to reach a specific frequency of water quality target at multiple assessment points.

\subsubsection{The targeting of upstream PMAs}

In step 1, the river network information was extracted from a digit elevation map (DEM) using the hydrology module of ArcGIS. As shown in Fig. 2a, AP-1 and AP-2 were placed at the outlets of sub-watershed no. 67 and 80, respectively. 

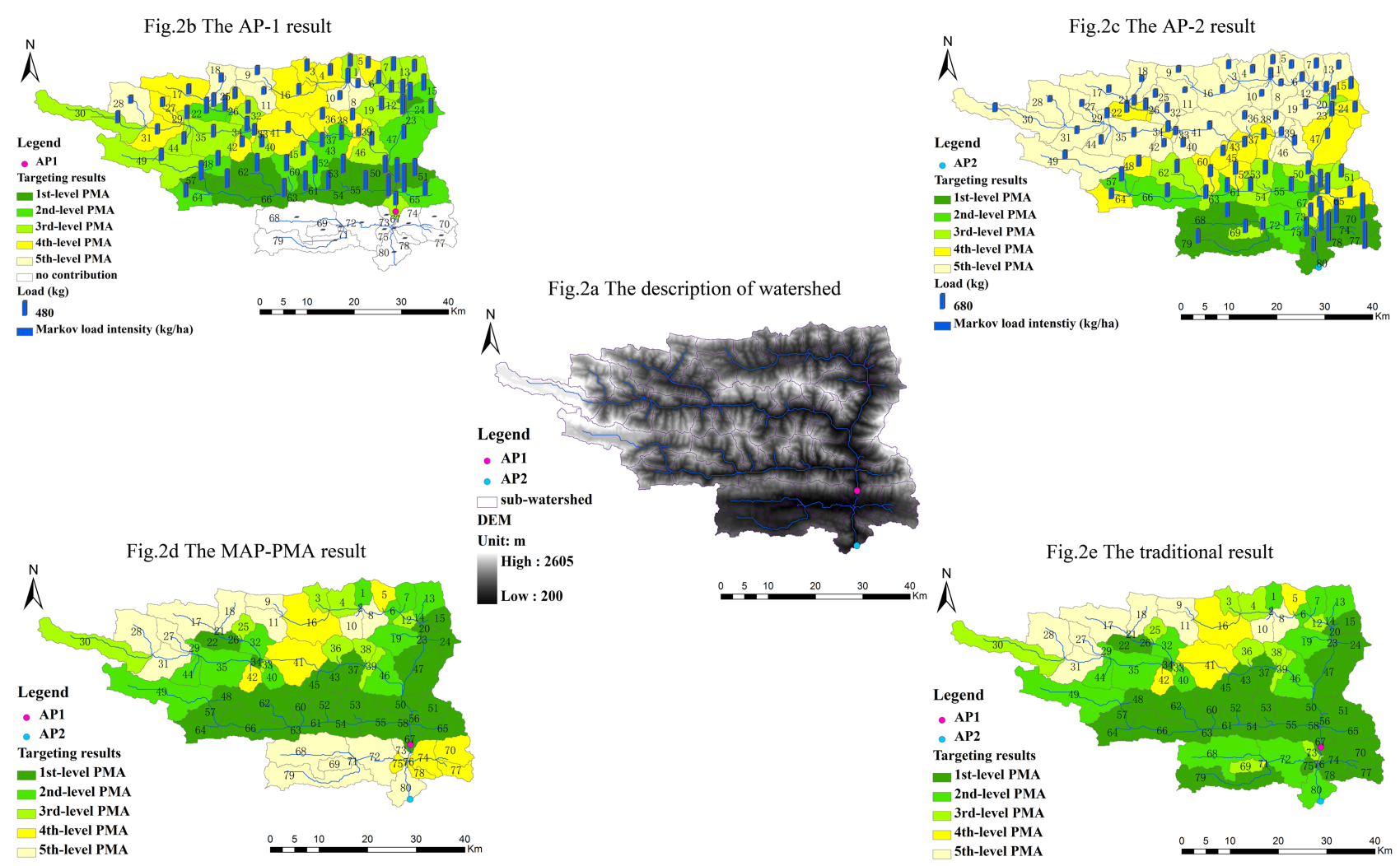

Fig. 2. The targeting results of the MAP-PMA, the AP-1, the AP-2, and traditional approach.

Traditionally, the upstream pollutant inputs are assumed to transport semi-systematically downstream. In the MAPPMA framework, this classical continuum idea was replaced by a hierarchical idea, in which the river network is divided into smaller river sections between multiple assessment points (Brierley and Fryirs, 2011; Miller et al., 2012, 2013). Each river section represents a homogeneous spatial unit, which associated with a specific assessment point within the river network.

In step 2, a multi-level PMA (ML-PMA) approach, recommended by our previous study, was used successively for each river section through the river network. The ML-PMA approach, which integrates both watershed and river processes, was proposed by integrating a watershed model, a stream model and a Markov chain method. The detailed processes involve the following three steps.

Step 2-1: the watershed processes were simulated using the Soil Water Assessment Tool (SWAT) (Arnold et al., 1998). In our previous studies (Shen et al., 2012, 2013, 2008, 2010), the SWAT model was applied in the Daning River watershed to quantify the pollutant loads released from each subwatershed. In this research, the flow and P yields were obtained from our constructed SWAT model.

Step 2-2: the in-stream processes for each river section were simulated by the Qual2kw (Brown and Barnwell, 1987). For loose modeling, the SWAT results were used as model inputs to the river process model (Wu et al., 2006). More information about these two models and the calibration processes can be obtained from our related studies (Shen et al., 2012, 2013, 2008, 2010). Following model calibration (Gong et al., 2011; Shen et al., 2012, 2013), a 10-year modeling period was performed to isolate climate change and land use change.

Step 2-3: lastly, the total pollutant fluxes at certain assessment point were separated, in terms of their origin subwatersheds, by the Markov matrix calculation provided by Grimvall and Stalnacke (1996). In this respect, those upstream sub-watersheds were characterized and ranked based on their load contributions to the water quality at certain assessment points. Compared to the required water quality standard of China (GB3838-2002), the total phosphorus (TP) concentration " $<0.1 \mathrm{mg} \mathrm{L}^{-1}$ " was considered as the water quality target for both AP-1 and AP-2. Thereafter, those multiple levels of PMAs corresponded to the upgrading of the frequency of this water quality target. More details about the ML-PMA approach can be found in our previous study.

\subsubsection{The targeting of downstream PMAs}

Following step 2, after allocating the required load reductions among the upstream sub-watersheds, the water quality at the upstream assessment point was assumed to reach the 
required level. In steps 3 and 4, the concept of "connectivity", mentioned by Hooke (2003), was used to refer to the response of the pollutant fluxes at the nearby downstream point to the variation of upstream inputs (Buchanan et al., 2013). In this respect, the response of the downstream pollutant fluxes was quantified based on the variation of the upstream inputs if these two assessment points were hydrologically connected. Assume the flow, pollutant load and concentration during the baseline period can be marked as $q_{1}, \ldots, q_{j}, \ldots, q_{k}$; $\operatorname{load}_{1}, \ldots, \operatorname{load}_{j}, \ldots, \operatorname{load}_{k} ;$ and $c_{1}, \ldots, c_{j}, \ldots, c_{k}$, respectively, for each assessment point. To reach the water quality target, the load reduction requirement at each river point was calculated as $\Delta E_{1}, \ldots, \Delta E_{j}, \ldots, \Delta E_{k}$, which can be expressed as follows:

$$
\Delta E_{j}=31.54 \times\left(C_{j} q_{j}-C_{j s} q_{j s}\right),
$$

where $\Delta E_{j}$ represents the required load reduction at assessment point $e_{i}$ (t year $\left.{ }^{-1}\right), q_{i}$ and $C_{i}$ represent the flow $\left(\mathrm{m}^{3} \mathrm{~s}^{-1}\right)$ and water quality $\left(\mathrm{mg} \mathrm{L}^{-1}\right)$, respectively, during the baseline period, and $q_{j s}$ and $C_{j s}$ represent the required water quality target $\left(\mathrm{mg} \mathrm{L}^{-1}\right)$ and the corresponding flow $\left(\mathrm{m}^{3} \mathrm{~s}^{-1}\right)$, respectively. Over a long period, the flow volume can be assumed to stay unaffected, so Eq. (1) becomes

$\Delta E_{i}=31.54 \times\left(C_{i}-C_{i s}\right) q_{i}$.

If $C_{i}<C_{j s}, \Delta E_{j}$ is defined as 0. In this respect, there is no further load reduction requirement at the downstream assessment point. In step 2, the river retention potentials between each pair of assessment points were quantified based on the method given by Grimvall and Stalnacke (1996) and expressed by the following matrix:

$Z=\left\{\begin{array}{cccc}\alpha_{11} & \alpha_{12} & \cdots & \alpha_{1 k} \\ \alpha_{21} & \alpha_{22} & \cdots & \alpha_{2 k} \\ \vdots & \vdots & \ddots & \vdots \\ \alpha_{k 1} & \alpha_{k 2} & \cdots & \alpha_{k k}\end{array}\right\}$,

where each matrix element represents the river retention potential between $e_{i}$ and $e_{j}$, which integrates the river transport aspects of NPS pollution. Thereafter, the response of pollutant fluxes at the nearby downstream point to the variation of upstream inputs can be quantified as follows:

$\Delta E_{j+1}^{,}=31.54 \times \sum_{j=1}^{m} \alpha_{j} \times \Delta E_{j}$,

where $\Delta E_{j+1}$ represents the variation of downstream pollutant fluxes (tyear) ${ }^{-1}$, and $m$ represents the number of its upstream tributaries.

In the following steps, the value of $\Delta E_{j+1}$ was compared to the required load reduction at the nearby downstream assessment point. If $\Delta E_{j+1} \geq \Delta E_{j+1}$, the changed water quality can be assumed to have reached the required water quality target. For a more effective allocation of those downstream
PMAs, no further load reductions are needed, and thus the downstream sub-watersheds are identified as the low-level PMAs. Otherwise, if $\Delta E_{j+1}<\Delta E_{j+1}$, the load reduction requirement at this point is $\Delta E_{j+1}-\Delta E_{j+1}$. Thereafter, those multi-level PMAs were re-identified based on this changed load reduction requirement. Finally, the MAP-PMA framework determined whether there were any more downstream assessment points. If there were any other assessment points, this algorithm proceeded to the next nearby downstream point. If there were none, this algorithm terminated. Contrary to conventional wisdom, the multiple levels of PMAs for a given large watershed or a complex river network are allocated from upstream to downstream.

\section{Results and discussion}

\subsection{The comparison between multiple- and single- assessment points results}

Based on the framework of MAP-PMAs, the ranking result of each sub-watershed could be obtained, which provided the basis of multiple-level PMAs. In this section, the targeting results of multiple- and single-assessment point PMAs are compared. As shown in Table 1, the TP concentration over the period of $2000-2009$ ranges from 0.07 to $0.27 \mathrm{mg} \mathrm{L}^{-1}$ at AP-1 and 0.07 to $0.17 \mathrm{mg} \mathrm{L}^{-1}$ at AP-2. Therefore, the required TP load reductions were quantified as $16.43,30.29$, 50.00, and $64.12 \%$ at AP-1 and 7.02, 23.21, 29.66, and $43.99 \%$ at AP-2, respectively. The current frequency of water quality target was approximately $60 \%$, so five range values, in terms of $<70 \%, 70-80 \%, 80-90 \%, 90-100 \%$ and $100 \%$ frequency, were used to illustrate the multiple levels of PMAs. To reach each frequency of water quality target, the load reductions at AP-1 were quantified as 101, 263, 453, and 610 tons. Likewise, the variations of TP fluxes at AP-2 were 96-148, 168-259, 300-463, and 378-582 tons during the period of 2000-2009. Specifically, if the water quality was targeted as $100 \%$ at AP-1, the frequency of this target at AP-2 increased from $60 \%$ to $100 \%$ as well. Conversely, if the water quality targets were set as 70,80 , and $90 \%$ at AP- 1 , the required load reduction at AP-2 leveled off from $23.21 \%$ in $2000,29.66 \%$ in 2002 , and $43.99 \%$ in 2003 to 12.07 , 18.00 , and $32.36 \%$, and $3.71,9.26$, and $23.64 \%$, and 0.00 , 0.00 , and $7.65 \%$. This result demonstrated that the upstream water quality had a great impact on the downstream pollutant fluxes. Therefore, the interactions between these river assessment points identified by the MAP-PMA integrate the upstream sources and the downstream transport aspects of the NPS pollution at the watershed scale.

As shown in Fig. 2b, the targeting results for AP-1 showed that a total $15.06,15.29,23.66,20.05$, and $10.13 \%$ of the upstream areas of AP-1 were identified as the 1st-, 2nd-, 3rd-, 4th-, 5th-level PMAs, respectively. These multiple levels of PMAs disproportionately contributed 25.90, 20.94, 27.04, 
Table 1. The TP load reduction requirements at the Wuxi station and the watershed outlet during the period of 2000 to 2009.

\begin{tabular}{|c|c|c|c|c|c|c|c|}
\hline \multirow[b]{2}{*}{ Period } & \multirow[b]{2}{*}{$\begin{array}{r}\text { Rainfall } \\
(\mathrm{mm})\end{array}$} & \multicolumn{3}{|c|}{ AP-1 } & \multicolumn{3}{|c|}{ AP-2 } \\
\hline & & Load (t) & $\begin{array}{r}\text { Concentration } \\
\qquad\left(\mathrm{mg} \mathrm{L}^{-1}\right)\end{array}$ & Exceed & Load (t) & $\begin{array}{r}\text { Concentration } \\
\left(\mathrm{mg} \mathrm{L}^{-1}\right)\end{array}$ & Exceed \\
\hline 2000 & 1111 & 952 & 0.27 & $64.12 \%$ & 1329 & 0.13 & $23.21 \%$ \\
\hline 2001 & 728 & 642 & 0.08 & $0 \%$ & 804 & 0.11 & $7.02 \%$ \\
\hline 2002 & 1082 & 871 & 0.14 & $30.29 \%$ & 1162 & 0.14 & $29.66 \%$ \\
\hline 2003 & 1444 & 865 & 0.20 & $50 \%$ & 1156 & 0.17 & $43.99 \%$ \\
\hline 2004 & 1028 & 618 & 0.12 & $16.43 \%$ & 782 & 0.07 & $0 \%$ \\
\hline 2005 & 1193 & 787 & 0.09 & $0 \%$ & 986 & 0.09 & $0 \%$ \\
\hline 2006 & 790 & 669 & 0.07 & $0 \%$ & 842 & 0.08 & $0 \%$ \\
\hline 2007 & 1254 & 723 & 0.09 & $0 \%$ & 909 & 0.09 & $0 \%$ \\
\hline 2008 & 1257 & 699 & 0.09 & $0 \%$ & 884 & 0.08 & $0 \%$ \\
\hline 2009 & 1240 & 680 & 0.09 & $0 \%$ & 875 & 0.08 & $0 \%$ \\
\hline
\end{tabular}

AP-1 represents the Wuxi station; AP-2 represents the watershed outlet.

19.40 and $6.72 \%$ of the TP fluxes at AP-1. On the aspect of spatial distribution, high-level PMAs were distributed among the areas adjacent to AP-1 and the Houxi River. Specifically, sub-watersheds no. 69-80 were not included in the targeting results of AP-1 because these sub-watersheds were located along the downstream of AP-1. Conversely, as shown in Fig. 2c, these sub-watersheds were identified as high-level PMAs for AP-2 because of their geographic locations adjacent to AP-2. This result indicated that there was a declining trend of load contribution of upstream areas from upstream to downstream assessment points, while the impact of those downstream sub-watersheds increased among multiple river points. The corresponding level PMAs for AP-2 accounted for $7.59,12.58,10.69,19.23$, and $50.91 \%$ of the total area and $14.48,16.73,13.23,18.32$, and $37.24 \%$ of the total TP fluxes.

On the aspect of the MAP-PMAs, the level of each downstream sub-watershed increased as the water quality target increased from $60 \%$ to $100 \%$ at AP-1. As shown in Table 2 , if the upstream water quality was targeted as $100 \%$, sub-watershed no. 68-80 were identified as 5th-level PMAs, indicating that there was no further required load reduction at AP-2. If the upstream water quality target was approximately $90 \%$, sub-watersheds no. 70 and 74-78 leveled off from 1st-level PMAs to 4th-level PMAs, while the remaining sub-watersheds were identified as 5th-level PMAs. This could be considered an important insight suggested by the MAP-PMA framework. Compared to the single point results, the interactions between upstream and downstream points are very helpful for a more cost-effective allocation of watershed PMAs, especially for those downstream areas. Furthermore, if the upstream water quality was targeted as $70 \%$ or $80 \%$, there were no 1 st-level and 5th-level PMAs among the downstream areas. This result indicated a maximum frequency of water quality target existed at the downstream river point $(90 \%$ at $\mathrm{AP}-2)$ if the pollutant removal potential at the upstream point was below a certain threshold. This could be considered another important insight provided by the MAPPMA framework. In general, the pollutant removal potential is usually below a specific threshold due to local economic or technical constraints (Domingo et al., 2007; Massoud et al., 2006; Sharpley et al., 1999; Sun et al., 2010; Zhang et al., 2009). From the economic point of view, to control the NPS pollution among multiple assessment points, emission trading is recommended as a more effective approach by producing a legal right of NPS pollution discharge and trading it as a commodity between upstream and downstream areas (Crutchfield et al., 1994).

\subsection{The comparison between the MAP-PMA and traditional targeting approach}

In this research, the MAP-PMA framework was based on a hierarchical idea, and the respective impacts of each spatial unit were separated from upstream to downstream. Comparatively, using the classical continuum idea, multiple assessment points were treated as an entirety by the traditional approach, and the identifying of PMAs generally focused on the highest impact of each spatial unit (Hefting et al., 2006). As shown in Fig. 2e, the corresponding levels of the traditional PMAs accounted for 50.00, 18.75, 13.75, 6.25, and $11.25 \%$ of the total number and $39.38,26.37,10.22$, 8.55 , and $15.13 \%$ of the total area of the Daning watershed. Clearly, the proportion of high-level MAP-PMAs was less than that of the traditional PMAs, while the percentile of lowlevel MAP-PMAs was much higher.

On the aspect of spatial distribution, no dramatic variations of PMAs were observed among the upstream areas adjacent to AP-1. This was because the river transport process stayed almost unaffected in the adjacent regions of AP1. Conversely, there was great variation between the MAPPMAs and traditional PMAs among the downstream areas. This can be explained by the fact that the MAP-PMA focused 
Table 2. The targeting results based on the MAP-PMAs in the Daning watershed.

\begin{tabular}{|c|c|c|c|c|c|c|c|c|}
\hline \multirow{2}{*}{$\begin{array}{r}\text { Sub- } \\
\text { watershed }\end{array}$} & \multirow{2}{*}{$\begin{array}{l}\text { Load } \\
\qquad(\mathrm{t})\end{array}$} & \multirow{2}{*}{$\begin{array}{r}\text { Cumulative } \\
\text { load (\%) }\end{array}$} & \multirow{2}{*}{$\begin{array}{l}\text { Cumulative } \\
\text { area }(\%)\end{array}$} & \multicolumn{5}{|c|}{ The targeting results } \\
\hline & & & & $60 \%$ & $70 \%$ & $80 \%$ & $90 \%$ & $100 \%$ \\
\hline 76 & 421 & $0.04 \%$ & $0.01 \%$ & $1 \mathrm{st}$ & 2nd & 2nd & 4th & 5 th \\
\hline 78 & 27748 & $2.44 \%$ & $0.86 \%$ & $1 \mathrm{st}$ & 2nd & 2nd & 4th & 5 th \\
\hline 77 & 441 & $2.47 \%$ & $0.88 \%$ & $1 \mathrm{st}$ & 2nd & 2nd & 4th & 5 th \\
\hline 70 & 43095 & $6.20 \%$ & $2.41 \%$ & $1 \mathrm{st}$ & 2nd & 2nd & 4th & 5 th \\
\hline 74 & 34153 & $9.15 \%$ & $3.72 \%$ & $1 \mathrm{st}$ & 2nd & 3rd & 4 th & 5 th \\
\hline 75 & 5749 & $9.65 \%$ & $4.00 \%$ & 1 st & 2nd & 3 rd & 4 th & 5 th \\
\hline 79 & 52010 & $14.15 \%$ & $7.24 \%$ & 2nd & 2nd & 3rd & 5 th & 5 th \\
\hline 68 & 61654 & $19.48 \%$ & $11.11 \%$ & 2nd & 2nd & 4th & 5 th & 5th \\
\hline 80 & 30135 & $22.09 \%$ & $13.01 \%$ & 2nd & $3 \mathrm{rd}$ & 4th & 5 th & 5 th \\
\hline 72 & 45054 & $25.98 \%$ & $15.92 \%$ & $3 \mathrm{rd}$ & $3 r d$ & 4th & 5 th & 5 th \\
\hline 73 & 4926 & $26.41 \%$ & $16.25 \%$ & $3 \mathrm{rd}$ & $3 r d$ & 4 th & 5 th & 5 th \\
\hline 69 & 9745 & $27.25 \%$ & $16.93 \%$ & 4th & 4 th & 4 th & 5 th & 5 th \\
\hline
\end{tabular}

on the pollutant load actually reaching those multiple assessment points. First, there was a general trend of reduced agricultural areas from upstream to downstream in the Daning watershed. This trend implied reduced P loss potentials among those downstream areas because agricultural lands generally induce a greater impact on the export of $\mathrm{P}$ than other land uses (Whitehead et al., 2007; Gong et al., 2011; Shen et al., 2012, 2013). Second, the upstream P concentrations have been diluted during the transport process because of the long hydrological residence time within the downstream river network (Arheimer and Brandt, 2000; Bae and Ha, 2006; Zhou and Gao, 2011). The P depletion and $\mathrm{P}$ consumption by phytoplankton is also important during the downstream in-stream transport. In this sense, traditional PMAs appeared to have higher loss potentials relative to certain assessment points. However, as indicated by Table 2, the upstream P fluxes were rarely translated into the nearby downstream assessment points. Therefore, those traditional PMAs are questionable because the adoption of the classical continuum idea hindered the documentation of the upstream input changes, especially with respect to limited time and resource constraints.

As shown in Fig. 2d, it is possible to delineate those sensitive areas from high to low through the MAP-PMA framework. Among the high-level MAP-PMAs, there is more opportunity to reduce a much larger quantity of the NPS pollutant transported to multiple assessment points. Therefore, it is more effective to implement best management practices (BMPs) in these high-level PMAs. Contrary to the conventional wisdom that BMPs are more effective adjacent to the watershed outlet (Hefting et al., 2006), it is demonstrated that more high-level MAP-PMAs are distributed among the adjacent areas of the upstream river point. In this sense, it is recommended that the NPS pollutant could be best controlled among the upstream high-level PMAs adjacent to AP-1, and also by preventing the $\mathrm{P}$ exports from the downstream areas to protect the water quality of the entire watershed.

\section{Conclusions}

In this research, a MAP-PMA framework was proposed for aiding the targeting of PMAs, especially for large-scale watersheds. Compared to single assessment point results, the MAP-PMA framework integrated the upstream inputs and the downstream transport aspects of NPS pollution at the watershed scale. Based on the results obtained from this research, the integration of the upstream input changes was vital for the final PMA map, especially for a more costeffective allocation of those downstream PMAs. From this study, a maximum frequency of water quality target existed at the downstream river point if the pollutant removal potential at the upstream point was below a certain threshold. Contrary to the conventional wisdom, it is recommended that the NPS pollutant could be best controlled among the upstream high-level PMAs in protecting the water quality of the entire watershed.

The major error of the MAP-PMA may come from the selection process of multiple assessment points. In this research, the existing water quality monitoring stations were chosen as multiple assessment points where such were available. However, these stations were designed as a monitoring network for point-source pollution and may not refer to the perspective of the NPS pollution. Therefore, with the aid of the MAP-PMA, the resolution of the current monitoring network should be improved. It is believed that the optimal design of the monitoring network, together with the MAP-PMA framework, would provide a valuable tool for effectively allocating state funds for the establishment of conservation practices where they are needed. 
Acknowledgements. The study was supported by the National Science Foundation for Innovative Research Group (no. 51121003), the National Science Foundation for Distinguished Young Scholars (no. 51025933), the Fundamental Research Funds for the Central Universities, and China postdoctoral science foundation funded project.

The authors wish to express their gratitude to Hydrology and Earth System Sciences, as well as to the anonymous reviewers who helped to improve this paper though their thorough review.

Edited by: Y. Cai

\section{References}

Alexander, R. B., Smith, R. A., and Schwarz, G. E.: Effects of stream channel size on the delivery of nitrogen to the Gulf of Mexico, Nature, 403, 758-761, 2000.

Arheimer, B. and Brandt, M.: Watershed modelling of nonpoint nitrogen losses from arable land to the Swedish coast in 1985 and 1994, Ecol. Eng., 14, 389-404, 2000.

Arnold, J. G., Srinivasan, R., Muttiah, R. S., and Williams, J. R.: Large area hydrologic modeling and assessment Part I: Model development, J. Am. Water Resour. As., 34, 73-89, 1998.

Bae, M. S. and Ha, S. R.: Nonlinear regression approach to evaluate nutrient delivery coefficient, Water Sci. Technol., 53, 271-279, 2006.

Behera, S. and Panda, R. K.: Evaluation of management alternatives for an agricultural watershed in a sub-humid subtropical region using a physical process based model, Agr. Ecosyst. Environ., 113, 62-72, 2006.

Böhlke, J. K. and Denver, J. M.: Combined use of groundwater dating, chemical, and isotopic analyses to resolve the history and fate of nitrate contamination in two agricultural watersheds, Atlantic Coastal Plain, Maryland, Water Resour. Res., 31, 23192339, 1995.

Brierley, G. J. and Fryirs, K.: Variability in sediment delivery and storage along river courses in Bega catchment, NSW, Australia: implications for geomorphic river recovery, Geomorphology, 38, 237-265, 2011.

Brown, L. C. and Barnwell, T. O.: The Enhanced Stream Water Quality Models QUAL2E and QUAL2E-UNCAS, EPA, US, Environmental Protection Agency, Athens, GA, 189-192, 1987.

Carpenter, S. R., Caraco, N. F., Correll, D. L., Howarth, R. W., Sharpley, A. N., and Smith, V. H.: Nonpoint pollution of surface waters with phosphorus and nitrogen, Ecol. Appl., 8, 559-568, 1998.

Crutchfield, S. R., Letson, D., and Malik, A. S.: Feasibility of pointnonpoint source trading for managing agricultural pollutant loadings to coastal waters, Water Resour. Res., 30, 2825-2836, 1994.

Domingo, J. W. S., Bambic, D. G., Edge, T. A., and Wuertz, S.: Quo vadis source tracking? Towards a strategic framework for environmental monitoring of fecal pollution, Water Res., 41, 35393552, 2007.

Gérard-Marchant, P., Hively, W. D., and Steenhuis, T. S.: Distributed hydrological modelling of total dissolved phosphorus transport in an agricultural landscape, part I: distributed runoff generation, Hydrol. Earth Syst. Sci., 10, 245-261, doi:10.5194/hess-10-245-2006, 2006.
Ghebremichael, L. T., Veith, T. L., and Hamlett, J. M.: Integrated watershed- and farm-scale modeling framework for targeting critical source areas while maintaining farm economic viability, J. Environ. Manage., 114, 381-394, 2013.

Gong, Y., Shen, Z., Hong, Q., Liu, R., and Liao, Q.: Parameter uncertainty analysis in watershed total phosphorus modeling using the GLUE methodology, Agr. Ecosys. Environ., 142, 246-255, 2011.

Grimvall, A. and Stalnacke, P.: Statistical methods for source apportionment of riverine loads of pollutants, Environmetrics, 7, 201-213, 1996.

Hefting, M., Beltman, B., Karssenberg, D., Rebel, K., van Riessen, M., and Spijker, M.: Water quality dynamics and hydrology in nitrate loaded riparian zones in the Netherlands, Environ. Pollut., 139, 143-156, 2006.

Hooke, J.: Coarse sediment connectivity in river channel systems: a conceptual framework and methodology, Geomorphology, 56, 79-94, 2003.

Horton, R.: Erosion development of streams and their drainage watersheds; hydrophysical approach to quantitative morphology, GSA, 56, 275-370, 1945.

Kang, S., Lin, H., Gburek, W. J., Folmar, G. J., and Lowery, B.: Baseflow nitrate in relation to stream order and agricultural land use, J. Environ. Qual., 37, 808-816, 2008.

Kovacs, A., Honti, M., Zessner, M., Eder, A., Clement, A., and Bloschl, G.: Identification of phosphorus emission hotspots in agricultural catchments, Sci. Total Environ., 433, 74-88, 2012.

Lee, J. G., Selvakumar, A., Alvi, K., Riverson, J., Zhen, J. X., Shoemaker, L., and Lai, F.: A watershed-scale design optimization model for stormwater best management practices, Environ. Modell. Softw., 37, 6-18, 2012.

Liu, Z. J. and Weller, D. E.: A stream network model for integrated watershed modeling, Environ. Modell. Assess., 13, 291303, 2008.

Massoud, M. A., El-Fadel, M., Scrimshaw, M. D., and Lester, J. N.: Factors influencing development of management strategies for the Abou Ali River in Lebanon I: Spatial variation and land use, Sci. Total Environ., 362, 15-30, 2006.

Meybeck, M.: Man and river interface: Multiple impacts on water and particulates chemistry illustrated in the seine river watersheds, Hydrobiologia, 374, 1-20, 1998.

Meynendonckx, J., Heuvelmans, G., Muys, B., and Feyen, J.: Effects of watershed and riparian zone characteristics on nutrient concentrations in the River Scheldt Basin, Hydrol. Earth Syst. Sci., 10, 913-922, doi:10.5194/hess-10-913-2006, 2006.

Miller, J. R., Lord, M., Villarroel, L. F., Germanoski, D., and Chambers, J.: Structural organization of process zones in upland watersheds of central nevada and its influence on basin connectivity, dynamics, and wet meadow complexes, Geomorphology, 139140, 384-402, 2012.

Miller, J. R., Mackin, G., Lechler, P., Lord, M., and Lorentz, S.: Influence of basin connectivity on sediment source, transport, and storage within the Mkabela Basin, South Africa, Hydrol. Earth Syst. Sci., 17, 761-781, doi:10.5194/hess-17-761-2013, 2013.

Prasad, V. K., Ortiz, A., Stinner, B., McCartney, D., Parker, J., Hudgins, D., Hoy, C., and Moore, R.: Exploring the relationship between hydrologic parameters and nutrient loads using digital elevation model and GIS-A case study from Sugarcreek Headwaters, Ohio, USA, Environ. Monit. Assess., 110, 141-169, 2005. 
Rodriguez-Iturbe, I. and Rinaldo, A.: Fractal river basins, chance and self- organization, Cambridge Univ. Press, Cambridge, UK, 1997.

Setegn, S. G., Srinivasan, R., Dargahi, B., and Melesse, A. M.: Spatial delineation of soil erosion vulnerability in the Lake Tana Basin, Ethiopia, Hydrol. Process., 23, 3738-3750, 2006.

Sharpley, A. N., Gburek, W. J., Folmar, G., and Pionke, H. B.: Sources of phosphorus exported from an agricultural watershed in Pennsylvania, Agr. Water Manage., 41, 77-89, 1999.

Shen, Z., Hong, Q., Yu, H., and Niu, J. F.: Parameter uncertainty analysis of the non-point source pollution in the Daning River watershed of the Three Gorges Reservoir Region, China, Sci. Total Environ., 405, 195-205, 2008.

Shen, Z., Hong, Q., Yu, H., and Niu, J. F.: Parameter uncertainty analysis of non-point source pollution from different land use types, Sci. Total Environ., 408, 1971-1978, 2010.

Shen, Z., Chen, L., Liao, Q., Liu, R., and Hong, Q.: Impact of spatial rainfall variability on hydrology and nonpoint source pollution modeling, J. Hydrol., 472-473, 205-215, 2012.

Shen, Z., Chen, L., Liao, Q., Liu, R., and Huang, Q.: A comprehensive study of the effect of GIS data on hydrology and non-point source pollution modeling, Agr. Water Manage., 118, 93-102, 2013.

Squillace, P. J. and Thurman, E. M.: Herbicide transport in rivers: importance of hydrology and geochemistry in nonpoint-source contamination, Environ. Sci. Technol., 26, 538-545, 1992.

Strauss, P., Leone, A., Ripa, M. N., Turpin, N., Lescot, J. M., and Laplana, R.: Using critical source areas for targeting costeffective best management practices to mitigate phosphorus and sediment transfer at the watershed scale, Soil Use Manage., 23, 144-153, 2007.

Sun, Y., Zhou, Q., Xie, X., and Liu, R.: Spatial, sources and risk assessment of heavy metal contamination of urban soils in typical regions of Shenyang, China, J. Hazard. Mater., 174, 455-462, 2010.
Tripathi, M. P., Panda, R. K., and Raghuwanshi, N. S.: Identification and prioritisation of critical sub-watersheds for soil conservation management using the SWAT model, Biosyst. Eng., 85, 365-379, 2003.

White, M. J., Storm, D. E., Busteed, P. R., Stoodley, S. H., and Phillips, S. J.: Evaluating Nonpoint Source Critical Source Area Contributions at the Watershed Scale, J. Environ. Qual., 38, 1654-1663, 2009.

Whitehead, P. G., Heathwaite, A. L., Flynn, N. J., Wade, A. J., and Quinn, P. F.: Evaluating the risk of non-point source pollution from biosolids: integrated modelling of nutrient losses at field and catchment scales, Hydrol. Earth Syst. Sci., 11, 601-613, doi:10.5194/hess-11-601-2007, 2007.

$\mathrm{Wu}, \mathrm{B}$. and Zheng, Y.: Assessing the value of information for water quality management: a watershed perspective from China, Environ. Monit. Assess., 185, 3023-3035, 2013.

Wu, J., Yu, S. L., and Zou, R.: A water quality-based approach for watershed wide BMP strategies, J. Am. Water Resour. As., 42, 1193-1204, 2006.

Yeghiazarian, L. L., Walker, M. J., Binning, P., Parlange, J. Y., and Montemagno, C. D.: A combined microscopic and macroscopic approach to modeling the transport of pathogenic microorganisms from nonpoint sources of pollution, Water Resour. Res., 42, 1-17, 2006.

Zhang, Y., Guo, F., Meng, W., and Wang, X. Q.: Water quality assessment and source identification of Daliao river basin using multivariate statistical methods, Environ. Monit. Assess., 152, 105-121, 2009.

Zhou, H. and Gao, C.: Assessing the Risk of Phosphorus Loss and Identifying Critical Source Areas in the Chaohu Lake Watershed, China, Environ. Manage., 48, 1033-1043, 2011. 